\title{
Premio Nacional a la Investigación Médica 2016
}

\section{National Prize for Medical Research}

Correspondencia

Ciro Maguiña Vargas

ciro.maguina@upch.pe

Recibido: 09/12/2016 Aprobado: 12/12/2016

Citar como: Calvo Quiroz A, Maguiña Vargas C. Premio Nacional a la Investigación Médica 2016. Acta Med Peru. 2016;33(4):265-6

\author{
Armando Calvo Quiroz ${ }^{1,2,3}$, Ciro Maguiña Vargas ${ }^{2,3,4}$ \\ 1 Presidente del Comité Nacional de Investigación, Colegio Médico del Perú. Lima, Perú. \\ 2 Universidad Peruana Cayetano Heredia. Lima, Perú. \\ ${ }^{3}$ Hospital Nacional Cayetano Heredia. Lima, Perú. \\ ${ }^{4}$ Vicedecano Nacional, Colegio Médico del Perú. Lima, Perú.
}

La investigación en el Perú está presente desde los tiempos inmemoriales; los Paracas 700 años a. c. realizaban trepanaciones utilizando el Tumi, hoy símbolo del CMP, y para llegar a este nivel de experticia debían recurrir al conocimiento empírico, a la prueba y error, embrión del conocimiento científico ${ }^{[1]}$.

Hoy la historia nos recuerda una larga lista de investigadores médicos desde Daniel Alcides Carrión, Alberto Barton, Carlos Monge Medrano, Hugo Lumbreras, Hernán Miranda y otros tantos que es imposible enumerar a todos en el presente artículo.

Un ejemplo actual de la contribución permanente de los médicos peruanos a la medicina universal, es el desarrollo del método de susceptibilidad a drogas por observación microscópica (MODS) reconocido por la Organización Mundial de Salud para el diagnóstico rápido de la infección tuberculosa y su sensibilidad antibiótica, que no solo destaca por sus bondades diagnósticas, sino también porque sus autores han cedido la patente a la humanidad mostrando un desprendimiento que los enaltece ${ }^{[2]}$.

Pero necesitamos una mayor número de investigaciones, requerimos respuesta a innumerables interrogantes, algunas ya presentes y otras generándose en los constantes cambios por los que atraviesa nuestra patria.

Los problemas de salud que aquejan a nuestros compatriotas son antiguos y nuevos; el cambio de la pirámide poblacional nos enfrenta a complejas situaciones de salud correspondientes a una nación joven y a una desarrollada; nos preocupan tanto la mortalidad materna infantil como el incremento de la obesidad y las enfermedades no transmisibles. Vivir insertos en el mundo, con un incremento de turistas, nos hace propensos a la expansión de epidemias como la Chikungunya, Zika; el uso indiscriminado de la Internet nos enfrenta a nuevas formas de adicción o violencia, el bullying escolar en las redes o el acoso online de los niños; los desastres naturales que periódicamente vive nuestro país, como los terremotos, huaycos y heladas, acarrean riesgos para la salud que debemos sortear, que los médicos debemos ayudar a resolver.

Por todo ello es preciso continuar investigando, y el Colegio Médico del Perú considerando la investigación como una actividad fundamental del quehacer médico, creó el Premio Nacional a la Investigación Médica con la finalidad de estimular y promover esta actividad entre los miembros de la orden. 
El 2010 el Colegio Médico del Perú instauró el Premio a la Investigación el cual se desarrolló durante los años 2010, 2011, 2012, 2013. Lamentablemente la gestión del 2014.2015 optó por anularla. Hoy el 2016 se ha otorgado el Premio Nacional "Daniel Alcides Carrión" a la investigación "Concentración de lactoferrina en la lecha materna de madres de recién nacidos de bajo peso al nacer" de los autores: Christie Gloria Turin More, Alonso Zea Vera, María S. Rueda Altez, César P. Carcamo y Theresa Ochoa Woodell, trabajo que ganó también el primer lugar en la Macro Región Lima y Callao "Alberto Barton".

En la Macro Región Norte "Hernán Miranda Cueto" ganó el primer lugar el trabajo "Nivel de adherencia y factores que influyen en la suplementación y tratamiento con sulfato ferroso y ácido fólico en gestantes que acuden al establecimiento de salud Toribio Castro Chirinos - Lambayeque 2016" de los autores: Jorge Luis Fernández Mogollón, Cristhian Cervera Varias, Cenia Gutiérrez Llerena, Yeyson Huamán Díaz y Harlind Huamán Díaz.

En la Macro Región Centro "Carlos Monge Medrano" ganó el primer lugar el trabajo "Factores de riesgo cardiovascular y disfunción endotelial en adultos nativos de gran altura" del autor Aníbal Valentín Díaz Lazo.

En la Macro Región Sur "Hugo Lumbreras Cruz" ganó el primer lugar el trabajo "Experiencia en traqueostomía percutánea por dilatación sin fibrobroncoscopio - Unidad de Cuidados Intensivos del Hospital Nacional Carlos Alberto Seguín Escobedo, Arequipa - 2011-2014" de los autores: Rafael Tapia Pérez, Miguel Barreda De la Cruz, Fabricio Oporto Gonzales, Pedro Alcázar Zuzunaga, Luis Fajardo Karlo, Javier Torres Angles e Yvan Pérez Vargas.

La experiencia del Premio Nacional a la Investigación Médica 2016 ha sido muy positiva y estimulante, el número de trabajos presentado fue de 113 trabajos y superó las anteriores convocatorias y demostró el interés del médico peruano en resolver los problemas de salud de los peruanos.

Entre los trabajos ganadores hemos encontrado preocupación y respuestas a problemas materno infantiles, quirúrgicos y organizacionales; a enfermedades cardiovasculares, oncologías, renales y diabetes.

\section{REFERENCIAS BIBLIOGRÁFICAS}

1. Galan-Rodas E, Laberiano Fernandez C, Maguiña Vargas C. Historia del Tumi: Símbolo de la Medicina Peruana y del Colegio Médico del Perú. Acta Med Peruana. 2012;29(1):56-8.

2. Pareja-Ramos JJ, Huamán-Orosco PC, Torres-Chang J. La prueba rápida MODS: Una necesidad creciente de descentralización en nuestro país Rev Med Hered. 2013;24(2):170-2.

\title{
Ahora puede enviar sus artículos para Acta Médica Peruana en nuestro Open Journal System:
}

\author{
www.amp.cmp.org.pe
}

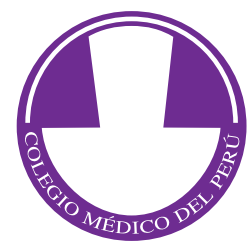

